\title{
Práticas em Psicologia na Saúde Pública: Aproximando Cenários e Contextos
}

\author{
Taise Signorini ${ }^{1}$ \\ ${ }^{1}$ Universidade Paranaense, \\ PR, Brasil.
}

\author{
Fátima Ferretti ${ }^{2}$ \\ ${ }^{2}$ Universidade Comunitária da Região de Chapecó, \\ SC, Brasil.
}

\author{
Maria Elisabeth Kleba da Silva ${ }^{2}$ \\ ${ }^{2}$ Universidade Comunitária da Região de Chapecó, \\ SC, Brasil.
}

\begin{abstract}
Resumo: Este estudo teve por objetivo desvelar as práticas realizadas com foco na saúde pública durante a graduação em um curso de psicologia de uma universidade privada do interior do estado do Paraná. Trata-se de uma pesquisa qualitativa. A coleta de dados aconteceu por meio da análise documental do Projeto Pedagógico do Curso e dos planos de ensino das disciplinas que abordavam temas voltados à saúde pública, bem como por meio de entrevista semiestruturada com a coordenação e da realização de dois grupos focais: o primeiro, com nove professores psicólogos, e o segundo, com 12 estudantes. A análise de dados do material empírico das entrevistas e dos grupos focais se deu por meio da análise de conteúdo temática. Observou-se que a maioria das práticas na saúde pública é realizada nos estágios obrigatórios, seja ele em atendimento clínico individual ou em grupo, em visita domiciliar, em plantão psicológico, em trabalho em grupo, entre outras modalidades. Tal condição, de certa forma, diminui o número de vivências realizadas pelos estudantes ao longo da formação em Psicologia. É importante destacar que o curso apresenta algumas práticas consideradas inovadoras no campo da saúde pública, como o consultório de rua e o atendimento em sala de espera. Há que se ampliar, contudo, a articulação entre ensino e prática, pois os avanços precisam acontecer principalmente no sentido de abranger, desde a formação, práticas mais integralizadas, de modo a comportar o encontro com outras áreas de formação e prover uma perspectiva, de certa forma, mais articulada e multiprofissional.
\end{abstract}

Palavras-chave: Saúde Pública, Formação Profissional, Ensino Superior, Psicologia.

\section{Practices in Psychology in Public Health: Approaching Scenarios and Contexts}

\begin{abstract}
This study aimed to analyze the practices conducted with a focus on public health during the graduation process in a Psychology Course at a private university in the state of Paraná, Brazil. This is a qualitative research, data was collected using documentary analysis of the Pedagogical Project of the Course and the teaching plans of the disciplines that deal with such issues, semi-structured interview with the coordination and two focus groups: the first, with nine professors psychologists, and the second, with 12 students. Data analysis of empirical material from the interviews and focus groups was done through analysis of thematic content. It has been observed that most practices in public health are performed in the mandatory stages, either clinical care (individual or in group), home visit, psychological center, group work, among others. Such condition, in a certain way, decreases the number of experiences conducted by students throughout the formation in Psychology. It is important to emphasize that the Course presents some practices considered innovative in what refers to practices related to public health, such as a street medical office and waiting room. However, the link between teaching and service must be broadened, because the advances need to happen mainly in the sense of encompassing, since the formation, more integrated practices to include the encounter with other areas of formation, providing, some form, a more articulated and multiprofessional perspective.
\end{abstract}

Keywords: Public Health, Professional Education, Higher Education, Psychology. 


\title{
Prácticas en Psicología en Salud Pública: Aproximando Escenarios y Contextos
}

\begin{abstract}
Resumen: Este estudio tuvo por objetivo desvelar las prácticas realizadas con foco en salud pública durante la graduación en psicología de una universidad privada del interior del estado de Paraná (Brasil). Esta es una investigación cualitativa. La recopilación de datos se ha realizado por medio del análisis documental del Proyecto Pedagógico del Curso y de los planes de enseñanza de las disciplinas que abordan tal temática, así como por entrevista semiestructurada con la coordinación y dos grupos focales: el primer, con nueve profesores psicólogos, y el segundo, con 12 estudiantes. El análisis de datos del material empírico de las entrevistas y de los grupos focales se dio por medio del análisis de contenido temático. Se ha observado que la mayoría de las prácticas en salud pública se realiza en las pasantías obligatorias, ya sea atención clínica (individual o en grupo), visita domiciliar, plantón psicológico, trabajo en grupo, entre otras. Tal condición, de cierta forma, disminuye el número de vivencias realizadas por los estudiantes a lo largo de la formación en Psicología. Es importante destacar que el curso presenta algunas prácticas consideradas innovadoras en lo que se refiere a salud pública, como consultorio de calle y atención en sala de espera. Hay que ampliarse, sin embargo, la articulación entre la enseñanza y el servicio, pues los avances deben suceder principalmente en el sentido de abarcar desde la formación, las prácticas más integrales, englobando otras áreas de formación y previendo una perspectiva, de cierta forma, más articulada y multiprofesional.
\end{abstract}

Palabras clave: Salud Pública, Formación Profesional, Enseñanza Superior, Psicología.

\section{Introdução}

A psicologia, como área de conhecimento das ciências humanas, precisou tencionar seus saberes para adentrar a área da saúde, pois nem sempre pertenceu a este campo, que, durante décadas, não esteve articulado à formação profissional do psicólogo (Guareschi, Dhein, Reis, Machry, \& Bennemann, 2009; Bernardes, 2012; Spink, 2013). Alguns acontecimentos contribuíram para a inserção da psicologia na saúde: na década de 1970, houve a inclusão de psicólogos na assistência à saúde pública, principalmente por conta do movimento de desospitalização e da expansão dos serviços de saúde mental; além disso, com todo esse movimento, os serviços de saúde mental foram estendidos à rede básica de saúde. Deste então, percebe-se uma maior inserção da psicologia nessa área (Dimenstein, 1999; Spink, 2013).

No processo de implantação do Sistema Único de Saúde (SUS), a atuação profissional na área da saúde precisou ser dinamizada, com algumas redefinições de responsabilidades entre os profissionais, os serviços de saúde e a formação profissional. Passaram a ser preconizadas práticas multiprofissionais e interdisciplinares que favorecessem um trabalho mais articulado, considerando-se todas as dimensões do ser humano - biológica, social, cultural, psicológica, ética, política - para potencializar uma ação integrada, possibilitando a compreensão ampliada do conceito de "saúde" de modo a concretizar outras formas de relação entre os sujeitos envolvidos no processo (Matos, Pires, \& Campos, 2009). A necessidade de mudanças na formação em saúde vem sendo amplamente debatida no Brasil, especialmente depois da aprovação das Diretrizes Curriculares Nacionais (DCN), a partir das quais se passou a compreender que a formação dos profissionais nessa área deve atender às necessidades sociais, com ênfase também na atuação dos profissionais da psicologia no SUS (Ceccim \& Feuerwerker, 2004).

Em consonância com essa realidade, as profissões que compõem as equipes atuantes no SUS, nos últimos anos, vêm direcionando sua formação para a necessidade de mudanças nos modelos pedagógicos com o intuito de desenvolver competências e habilidades nos egressos com vista a uma atuação de acordo com os princípios estabelecidos pelo sistema de saúde (Freitas, Colomé, Carpes, Backes, \& Beck, 2013; Leal, Melo, Veloso, \& Juliano, 2015). Busca-se que a formação problematize e integre saberes e práticas profissionais considerando as diversas demandas da saúde pública, 
os diferentes cenários e sujeitos e priorizando a atenção integral em saúde (Abrahão \& Merhy, 2014), já que a formação "pode ser um espaço privilegiado de construção de profissionais capazes de pensar a respeito das práticas que realizam, profissionais que se lançam ao exercício de reflexão" (Reis \& Guareschi, 2010, p. 865).

Ou seja, a formação precisa se desafiar e ser um ambiente privilegiado de "construção de profissionais capazes de pensar a respeito das práticas que realizam, profissionais que se lançam ao exercício da reflexão sobre a extensão das ações em Psicologia, principalmente daquelas vivenciadas nas atividades de estágio curricular" (Reis \& Guareschi, 2010, p. 865). As experiências de estágio devem se configurar-se como uma possibilidade para promover espaços que rompam com a lógica que busca a cientificidade produzida unicamente por meio de instrumentos e metodologias, o que gera uma visão unicamente técnica da psicologia enquanto ciência.

Percebe-se uma necessidade de que a formação dos profissionais da saúde esteja cada vez mais próxima da realidade da saúde da população assistida, e isto faz que mudanças - tanto educativas quanto organizativas, conceituais e ideológicas - sejam paulatinamente incorporadas ao processo de graduação (Batista, Carmona, \& Fonseca, 2014). Dentre as várias profissões da saúde, encontra-se a psicologia. A aproximação entre a psicologia e a saúde pública tem como propósito ampliar o campo de prática da profissão e organizar novos saberes capazes de contribuir para a promoção da saúde e qualidade de vida da população. A defesa da inserção do psicólogo nesse campo de atuação não pode se restringir aos propósitos da ampliação do mercado de trabalho, devendo se pautar na responsabilidade social inerente a todas as profissões que atuam na área da saúde.

Autores como Rotolo e Zurba (2011) e Vieira e Oliveira (2011) demonstraram a importância do profissional da psicologia na saúde pública, afirmando que o psicólogo deve ampliar suas formas de intervenção. A experiência prática vivida numa unidade de saúde coloca os estudantes em formação diante de toda a complexidade da área, em acordo com o relatado pelos autores acerca de uma extensão universitária realizada com um grupo de crianças denominado Grupo de Promoção à Saúde e Apoio ao Desenvolvimento Infantil: "descobrimos então que não bastava apenas saber e discursar sobre a necessidade de promover saúde e empoderar a comunidade, mas que isso deve ser construído de acordo com cada realidade local, a partir das experiências e anseios da própria comunidade." (Rotolo \& Zurba, 2011, pp. 135-136). Nessa direção, a forma como as práticas são organizadas durante o processo de formação profissional, em diferentes cenários e contextos, com diversas vivências e experiências, potencializa o desenvolvimento de competências para uma prática profissional que atente aos princípios do SUS.

Prática aqui será considerada a ação que concretiza um ensino, caracterizando-se pela aplicação de conceitos até então aprendidos teoricamente. Toda prática pressupõe em seu arranjo uma orientação por objetivos predeterminados e, assim, insere-se em um determinado contexto de conhecimento (Veiga, 1992). Conforme apontado por Seixas, CoelhoLima, Silva e Yamamoto (2013, p. 118), as práticas "referem-se ao modo como o curso operacionaliza os seus pressupostos teóricos, filosóficos e pedagógicos.” Já os cenários de prática são os locais onde realizam-se as atividades de estudo ou, ainda, onde serão desenvolvidas atividades práticas da formação profissional (Poppe \& Batista, 2012).

Partindo de tais premissas, o objetivo deste trabalho foi desvelar as práticas realizadas com foco na saúde pública durante o processo de formação profissional em um curso de psicologia do estado do Paraná a partir da ótica da coordenação, dos professores psicólogos e dos estudantes desse curso.

\section{Metodologia}

Trata-se de uma pesquisa qualitativa que permite aprofundar o estudo ao buscar compreender diversas possibilidades por possuir como matéria-prima a constituição de sentidos que se complementam: experiências, vivências, ações, considerações, entre outros (Minayo, 2012). Quanto ao método, utilizou-se o estudo de caso, que, segundo Yin (2007, p. 19), busca compreender o fenômeno numa perspectiva ampliada, já que "representa a estratégia preferida quando se colocam questões do tipo 'como' e 'por que', quando o pesquisador tem pouco controle sobre os eventos e quando o foco se encontra em fenômenos contemporâneos inseridos em algum contexto da vida real". Trata-se de uma investigação que prioriza um fenômeno dentro de um determinado contexto, baseando-se em diferentes fontes de evidência.

$O$ estudo se deu em um curso de psicologia de uma universidade privada do estado do Paraná no 
ano de 2016. Participaram do estudo a coordenação do curso, 9 dos 13 professores psicólogos convidados e 12 estudantes - do segundo, terceiro, quarto e quinto anos - que tinham vivências em programas de iniciação científica, projetos de extensão ou monitoria acadêmica, integrando as duas matrizes curriculares em andamento no momento da pesquisa.

A coleta de dados se deu inicialmente pela análise do ementário das disciplinas descritas no Projeto Pedagógico do Curso (PPC). Após a leitura das ementas, foram identificadas nove disciplinas que abordavam conteúdos na área da saúde pública, analisando-se seus planos de ensino na íntegra.

A análise documental do PPC e dos planos de ensino seguiu a análise de conteúdo temática referida por Minayo (2014). Operacionalmente, a análise de conteúdo temática divide-se em três etapas: pré-análise; exploração do material; e tratamento dos resultados obtidos e interpretação. Num primeiro momento, foram registradas informações colhidas e sistematizadas em um quadro criado para essa finalidade. Posteriormente, foi realizada a leitura flutuante do conteúdo do quadro, seguida do processo de codificação, do qual emergiram temas relevantes. Essa análise inicial instrumentalizou a pesquisadora no reconhecimento do contexto do curso estudado (Moreira, 2005).

Após essa primeira etapa, foram realizados uma entrevista semiestruturada com a coordenação do curso de graduação e dois grupos focais, guiados por um roteiro de questões preestabelecidas - o primeiro, com os professores, e o segundo, com os estudantes. Da mesma forma que a análise documental, os dados do material empírico das entrevistas e dos grupos focais foram examinados por meio da análise de conteúdo temática (Minayo, 2014).

A pesquisa foi aprovada pelo Comitê de Ética em Pesquisa Envolvendo Seres Humanos, sob o número 1.878.660. Para manter o sigilo, os professores foram nomeados pelas letras $\mathrm{P}$, acompanhados por números (P1, P2, P3 . . ); os estudantes, pela letra E números (E1, E2, E3 . . .); e a coordenação, pelas iniciais da nomenclatura do cargo (Coord.).

Todos os envolvidos na pesquisa assinaram o Termo de Consentimento Livre e Esclarecido (TCLE) e o Termo de Consentimento para Uso de Imagem e Voz.

\section{Análise e discussão dos dados}

Percebe-se que a maioria das práticas com foco na saúde pública é realizada nos estágios obrigatórios, que, nos cursos de psicologia, segundo as DCN, "visam assegurar o contato do formando com situações, contextos e instituições, permitindo que conhecimentos, habilidades e atitudes se concretizem em ações profissionais" (Conselho Nacional de Educação, 2011, p. 19). Tal constatação - de que as atividades práticas se restringem aos estágios - também é vista em uma pesquisa realizada em três instituições de ensino superior que possuem o curso de psicologia no Piauí (Silva \& Yamamoto, 2013). Ainda, segundo as DCN, os estágios devem ser estruturados em dois níveis, cada qual com carga horária própria: estágios básicos (pertencentes ao núcleo comum de formação) e estágios específicos (de acordo com as ênfases curriculares ofertadas em cada curso de psicologia). Nas diretrizes, estão previstas seis possibilidades de ênfases curriculares: a) psicologia e processos de investigação científica; b) psicologia e processos educativos; c) psicologia e processos de gestão; d) psicologia e processos de prevenção e promoção de saúde; e) psicologia e processos clínicos; e f) psicologia e processos de avaliação psicológica. Cada curso de psicologia deve ofertar, no mínimo, duas ênfases curriculares, sem prejudicar a formação generalista e sem configurar uma proposta de especialização, pois cada ênfase deve ser abrangente o suficiente para não caracterizar qualquer forma de especialização em determinada prática, local ou procedimento de atuação profissional em psicologia (Conselho Nacional de Educação, 2011). No curso analisado, as ênfases ofertadas eram "Psicologia e processos clínicos" e "Psicologia e processos psicossociais".

A realidade de concentrar as práticas nos estágios, de certa forma, diminui o número de vivências realizadas pelos estudantes na saúde pública ao longo da formação em psicologia, inclusive restringindo o "encontro" com alguns cenários de prática. Para concretizar exercícios em complexidade crescente, desde a observação até a prática assistida, o processo de formação precisa construir estratégias para que o estudante seja inserido precocemente nos cenários de prática do SUS, procurando acompanhar o fazer do psicólogo nesse contexto, seja nos estágios seja nas disciplinas do núcleo comum.

A partir da análise de conteúdo do material empírico e documental, emergiram subcategorias quanto aos tipos de práticas realizadas na área da saúde pública: atendimento clínico (individual ou em grupo), consultório de rua, visita domiciliar, plantão psicológico, sala de espera e trabalho em grupo. 
Quanto ao atendimento clínico (individual ou em grupo), uma das práticas realizadas nesse curso de psicologia, segundo os sujeitos deste estudo, é considerado o principal foco de atuação do profissional psicólogo e, ainda hoje, consiste na utilização do aporte teórico de diferentes linhas teóricas da psicologia para o entendimento e intervenção diante de situações conflituosas do sujeito ou do espaço por ele ocupado (Oliveira et al., 2004). Um estudo realizado em três cursos de psicologia no Ceará observou que estes também ainda organizam suas práticas centradas em uma proposta clínica tradicional, com o ensino voltado para um modelo intervencionista em saúde (Azevedo, Tatmatsu, \& Ribeiro, 2011). Neste estudo ora desenvolvido, a coordenação do curso detalha os estágios com esse foco:

... no quarto ano temos, hoje, o projeto de estágio que chamamos de "Doenças Crônicas". Estamos no Instituto do Rim, que é vinculado com o Sistema de Atenção Especializada e no CAPS AD, nestes locais fazemos atendimento clínico. Estamos também no Serviço de Atendimento Psicológico da cidade, lá fazemos atendimento clínico para crianças e adultos, individual e em grupos (Coord.).

No CAPS AD são desenvolvidos grupos com os usuários do local, esses grupos são abertos, sempre tem gente entrando e saindo. Eu sei que o objetivo é entender um pouco mais o que os levou ao uso de substâncias . . . com isso alguns deles conseguem, aos poucos, mudaram a perspectiva de vida (E3).

Cabe mencionar que essa constatação não está de acordo com o previsto pelas DCN em psicologia, pois, apesar dos avanços e das reestruturações curriculares, "a formação do psicólogo ainda é permeada hegemonicamente por uma proposta clínica tradicional, ofertando uma relevância mínima às questões referentes ao sistema de saúde vigente no país ..." (Azevedo et al., 2011, p. 259), aspecto que precisa ser redimensionado no processo de formação. No entanto, no curso em questão, percebe-se um avanço: há uma transposição da clínica para os espaços públicos, inclusive a partir de atendimentos grupais, como em alguns projetos de estágio que estão localizados na ênfase de processos clínicos, por exemplo: "A clínica psicológica no cotidiano da saúde pública" ou "Psicologia Analítica na saúde pública", conforme destacado no relato seguinte, de um professor: "Nós estamos também no Serviço de Atendimento Psicológico, que é um serviço específico da cidade. Realizamos atendimento clínico em grupo e individual para criança e adultos, porque esta é uma demanda da instituição" (P7).

Contudo, tal prática precisa ser tensionada enquanto aproximação da psicologia com o cenário das políticas públicas. Estudo realizado por Seixas e Yamamoto (2012) com 294 psicólogos inscritos no Conselho Regional de Psicologia do Rio Grande do Norte (CRP-RN) reforça essa ideia. O estudo observou que ainda hoje na psicologia existe a reprodução de valores liberais na atuação profissional, mesmo no campo das políticas sociais, com padrões clássicos de atuação profissional que se difundem em práticas apolíticas e acríticas. Torna-se importante questionar tais práticas na perspectiva de que elas podem não desenvolver habilidades necessárias para a atuação no contexto da saúde pública.

Nessa mesma direção, uma pesquisa realizada nos cursos de psicologia do Piauí em que se buscou apresentar reflexões sobre a formação para a saúde mental, evidenciou que, nos currículos dos três cursos estudados, mesmo aqueles que incorporaram os debates relacionados às políticas de saúde ainda mantêm nítida a dicotomia entre clínica e saúde pública (Macedo \& Dimenstein, 2011).

Deste modo, é importante que a academia represente um local de quebras de paradigmas quanto à formação profissional para atuação na saúde pública. Há de se refletir para além da centralidade da clínica psicológica como possibilidade de intervenção e encontro com o outro, pois, mesmo em locais que se propõem a trabalhar aspectos relacionados à saúde pública, a exclusiva manutenção de práticas de atendimento clínico individualizado se desvincula das propostas de intervenção previstas nas referências técnicas de atuação psicológica nesses espaços (Conselho Federal de Psicologia [CFP], 2013). Obviamente, não se nega a importância do atendimento clínico, mas este precisa ser redimensionado como prática para o campo da saúde pública.

Outra prática destacada nesta pesquisa realizada nos estágios que desenvolvem ações voltadas para o campo da saúde pública foi o consultório de rua. Este constitui-se como um dispositivo importante para a rede de saúde mental, pois busca reduzir, por meio de ações de promoção, prevenção e cuidados primários 
no espaço da rua, situações emergenciais como o uso excessivo de álcool e de outras drogas. Cabe destacar que os princípios norteadores de tal prática "são o respeito às diferenças, a promoção de direitos humanos e da inclusão social, o enfrentamento do estigma, as ações de redução de danos e a intersetorialidade" (Tondin, Barros Neta, \& Passos, 2013, p. 486). Segue relato da gestão do curso quanto a essa prática: "Estamos trabalhando com Políticas de DST/Aids que vêm sofrendo um sucateamento há muito tempo. Estamos retomando os princípios da abordagem da prevenção de DST/Aids através do consultório de rua" (Coord.).

É importante destacar que o consultório de rua é um serviço considerado relativamente novo no SUS. Constitui-se como prática a partir da necessidade de assistência em saúde para pessoas que se encontram em situação de rua, vinculado principalmente à problemática das drogas, das doenças sexualmente transmissíveis, como a aids, bem como a outras vulnerabilidades (Londero, Ceccim, \& Bilibio, 2014). Segundo o Conselho Federal de Psicologia (CFP, 2013), em sua cartilha de referências técnicas para atuação de psicólogas(os) em políticas públicas de álcool e outras drogas, o consultório de rua articula políticas públicas de saúde, por exemplo, a de saúde mental e de atenção primária à saúde, voltando-se ao atendimento de sujeitos em situação de vulnerabilidade que vivenciam dificuldade de acesso ou que não são assistidos pelos serviços de saúde local. Essa prática é relatada por professores e estudantes:

E tem o pessoal que está fazendo consultório de rua ... . Muito interessante também: trabalham com a comunidade em situação de rua. É uma oportunidade de entrarem em contato com uma prática diferenciada em psicologia, alguns autores falam em prática inovadora $(\mathrm{P} 7)$.

São seis estagiários do projeto de estágio da professora, três deles estão fazendo consultório de rua, vinculado ao serviço de saúde, trabalhando com prostitutas e travestis (E7).

Alguns estudos têm apontado o consultório de rua como uma prática importante na saúde pública, principalmente considerando-se seu alvo populacional, pois abrange sujeitos que estão em maior vulnerabilidade social. Cabe destacar aqui os resultados de uma pesquisa realizada em Alagoas que avaliou o consultório de rua na perspectiva de 18 pessoas em situação de rua atendidos por essa estratégia: a avaliação foi positiva, afirmando que se constitui num suporte social não apenas para questões relativas à saúde-doença, mas também para aspectos da vida cotidiana de quem reside na rua (Ferreira, Rozendo \& Melo, 2016). Outro estudo, realizado em Pernambuco e que buscou conhecer as práticas de saúde realizadas no cotidiano das equipes dos consultórios de rua com a participação de quinze trabalhadores de saúde, observou que essas práticas privilegiam o vínculo e o acolhimento das pessoas em situação de rua, reforçando a importância do trabalho em rede e da intersetorialidade na saúde (Silva, Frazão, \& Linhares, 2014).

Potencializar a inserção dessa prática na formação em psicologia parece-nos uma boa estratégia para uma maior aproximação dos estudantes com o cenário de saúde e com a realidade das populações vulneráveis. No entanto, no curso estudado, apenas alguns estudantes tiveram acesso a tal vivência, pois ela está vinculada a um projeto de estágio específico. Há de se construir mecanismos para implementar diferentes vivências na área da saúde pública para todos os estudantes.

A visita domiciliar também emergiu nas falas dos sujeitos da pesquisa como uma prática realizada na saúde pública. Ela possibilita ao estudante adentrar o espaço familiar e ter contato com demandas e potencialidades do local e da família. Deste modo, ela favorece o conhecimento das reais condições de vida de determinada família e permite o contato com a rotina familiar, o conhecimento do dia a dia, dos costumes, crenças, determinantes sociais, cultura, entre outros aspectos (Drulla, Alexandre, Rubel, \& Mazza, 2009).

Lá no Serviço de Atendimento Psicológico também
realizamos visita domiciliar . . . Os estagiários
entram em contato com realidades distintas ( $\mathrm{P} 7)$.

Eu entendo que é a oportunidade que os alunos possuem de entender esses sujeitos, a partir da visita domiciliar, em seus próprios territórios, no sentido mais amplo do termo 'território' mesmo. ... (P5).

A visita domiciliar é caracterizada como o deslocamento do profissional até o domicílio do usuário com finalidades específicas, por exemplo, de atenção à saúde. Neste sentido, assim como o consultório de rua para a psicologia, a visita domiciliar inicialmente tratou-se de uma prática em saúde vinculada ao processo 
de reconstrução da assistência em saúde mental a partir do processo de desospitalização (Pietroluongo \& Resende, 2007). Assim, a família é inserida no processo de tratamento e pode estar vinculada a vários locais de atendimento da saúde pública, como se percebe no caso dos estágios ora vinculados a um serviço de atendimento psicológico da Secretaria de Saúde do Município, ora à unidade básica de Saúde (UBS) e ao Núcleo de Apoio à Saúde da Família (NASF) - como destacado nas falas a seguir:

. . . naquela situação que a pessoa percebe sua necessidade, naquele momento, tem o psicólogo lá fazendo o acolhimento e as visitas domiciliares... nos projetos de estágio nas UBS ... (P2).

Uma outra professora, que não está aqui conosco neste momento, que tem estágio no NASF... está fazendo visitas domiciliares ... (P7).

Meu grupo de estágio realizou visitas domiciliares, fizemos estágio no NASF e acompanhamos a equipe em pelo menos cinco ou seis visitas... conseguimos perceber muitas coisas que só tínhamos visto na teoria, em sala de aula ... (E2).

A visita domiciliar foi apontada numa pesquisa com estagiários do último ano de um curso de graduação em psicologia como uma das principais práticas realizadas nos estágios: "Nos depoimentos, os estagiários também reconhecem a visita domiciliar como uma das diretrizes operacionais fundamentais tanto para a transformação da clínica como para a formação em psicologia" (Sousa \& Cury, 2009, p. 1436). Percebe-se a importância e potência de tal prática, pois permite que "o aluno tenha uma visão ampliada do paciente inserido na sua família e contexto sociocultural, se dispondo a um trabalho de parceria, colaboração e mútuo aprendizado." (RamosCerqueira, Torres, Martins, \& Lima, 2009, p. 277).

A visita domiciliar está inclusa nas propostas da atenção básica $(A B)$, principalmente quando se pensa nas equipes de saúde da família ou no próprio NASF. O "ir ao encontro" representa estar em contato com as demandas de atuação da saúde pública, que estiveram por muito tempo distantes do universo da psicologia como atuação profissional. Sendo assim, intensifica-se a importância de tal prática nos estágios relacionados à saúde pública.
Outra prática apontada como realizada na área da saúde pública foi o plantão psicológico. Sabe-se que este tem sido utilizado como um aporte de acolhida diante das demandas emergentes e instantâneas de ajuda psicológica ao colocar à disposição dos usuários que procuram pelo plantão um espaço de escuta aberto à pluralidade das demandas (Paparelli \& Nogueira-Martins, 2007). Isso segue brevemente descrito na fala de um estudante:

... o plantão psicológico é um tipo de atendimento psicológico, em forma de plantão, para a população em geral... (E11).

Nós ficamos à disposição dos usuários, ou mesmo da população, às vezes surge uma demanda, uma emergência e, estamos lá para atender esse sujeito... Já ouvi relatos bem diferentes no plantão, mas sempre são situações muito dificeis, por isso é importante ter o atendimento ali, de imediato (E10).

Cabe destacar que o plantão psicológico tem seus princípios técnicos baseados na acolhida, segundo os quais é ofertada uma atenção especial para a experiência do sujeito que procura ajuda em determinado momento - isso inclui não apenas a escuta tradicional da sua queixa, mas do modo como vivencia essa queixa, dos seus recursos subjetivos que permeiam seu contexto sociopsicológico e que servem para dar conta do seu sofrimento, além da atenção às expectativas que o sujeito possui para com a busca de auxílio (Schmidt, 2004). Neste sentido, o plantão pode-se inserir dentro de instituições que possuem relação direta com a área da saúde pública, conforme detalhado neste relato: "Tem grupo, por exemplo, de estágio específico, que faz plantão psicológico dentro das instituições, por exemplo dentro do Serviço de Atendimento Psicológico..." (E10).

Como será apresentado na fala da professora a seguir, o plantão psicológico é entendido como uma prática contemporânea para a psicologia, como uma nova modalidade da clínica psicológica. Trata-se de uma prática que se adequa às modalidades mais atuais de atendimento, voltada para a atenção psicológica em saúde do tipo emergencial que proporciona escuta e acolhimento em momentos de crise, não com vistas ao aprofundamento da problemática apresentada, mas à compreensão assertiva do sofrimento apresentado pelo indivíduo (Rebouças \& Dutra, 2010). 
"No Serviço de Atendimento Psicológico é realizada a prática de plantão psicológico, que também é uma prática vista como prática inovadora dentro do campo da saúde... (P7)". Mais uma vez, percebe-se, por meio desta fala, a apresentação de um local específico do município relacionado com a saúde pública e onde estão inseridos estagiários do curso de psicologia que desenvolvem o plantão psicológico. Uma pesquisa realizada com 27 estudantes da graduação de uma universidade do Paraná que relatou a experiência de implantação do plantão psicológico evidenciou positiva significação dos acolhimentos proporcionados por essa prática, além de reconhecimento do plantão como um lugar em que diversas questões podem ser ouvidas e valorizadas (Pan, Zonta, \& Tovar, 2015).

O plantão psicológico foi denominado como um encontro entre o terapeuta e a pessoa que busca pelo plantão psicológico (Doescher \& Henriques, 2012). Para Rebouças e Dutra (2010), o plantão psicológico pode contribuir para o alívio de crises, principalmente por ter uma caracterização que envolve o acolhimento imediato assim como a escuta empática, podendo ser considerado um desdobramento da prática clínica que adentra outros espaços ou, em outras palavras, uma prática clínica da contemporaneidade.

Outra prática relatada pelos sujeitos do estudo, nessa mesma perspectiva, foi a sala de espera. Esta se caracteriza pelo local da espera em que geralmente se aguarda alguma espécie de atendimento. Esse espaço é um território dinâmico, onde ocorrem mobilizações de diferentes pessoas e situações; um espaço que carece de diferentes intervenções que possam proporcionar algum alívio diante das angústias produzidas, já que geralmente a sala de espera se concentra em ambientes de serviços de saúde ou de assistência. Nas salas de espera, geralmente, " as pessoas conversam, trocam experiências entre si, observam, emocionam-se e expressam-se, ou seja, as pluralidades emergem por meio do processo interativo, que ocorre por meio da linguagem ..." (Teixeira \& Veloso, 2006, p. 321). Essas experiências podem ser aproveitadas como trocas que aliviam o sofrimento vivido naquele momento, como explicita uma professora do curso:

Nós estamos com prática, no meu projeto de estágio, em sala de espera na Associação dos Deficientes Físicos, que é um atendimento para deficientes fisicos custeado pelo SUS. Lá nós estamos fazendo uma prática diferenciada, que é sala de espera. . . (P7).
Foi muito interessante, no nosso estágio, a prática da sala de espera. Muita coisa acontece nas salas de espera, vivenciamos isso . . . Não imaginava que era possivel atendimento psicológico na sala de espera... (E10).

A prática sala de espera realiza a escuta ativa do sujeito, permitindo conhecer novas realidades num espaço anteriormente desconsiderado - local de espera de algum outro atendimento - e, por isso, vem sendo entendida como prática diferenciada em psicologia, muito usada em situações e instituições que possuem interface com a saúde de uma forma em geral (Rosa, Barth, \& Germani, 2011).

A sala de espera também pode ser utilizada como um espaço para desenvolver estratégia em educação em saúde. Pesquisa Santos, Andrade, Lima e Silva (2012) cujo objetivo foi descrever experiências de estudantes do curso de enfermagem monitoras do PETSaúde que realizavam ações com gestantes na sala de espera observou que esse espaço se transformou em um local de compartilhamento de experiências, afetos e socialização dos saberes técnico-científicos e populares. Além disso, como estratégia de educação em saúde, "oportunizou, na experiência aqui relatada, a aproximação da mulher gestante com o serviço, tornando-a protagonista de seu processo saúde-doença, ao mesmo tempo em que contribuiu para orientá-la em relação à sua corresponsabilidade." (Santos et al., 2012, p. 67).

Neste sentido, é pertinente ponderar que as práticas em sala de espera podem integrar vários estudantes da área da saúde ou afins - entre eles, o psicólogo -, numa intervenção interdisciplinar que concretize ações de educação em saúde com vistas a efetivar a participação dos usuários no processo de autocuidado. Entretanto, o que se percebeu é que são raras as práticas intercursos na área da saúde, o que fragiliza a formação dos futuros psicólogos quanto às experiências de práticas multi ou interdisciplinares, importante para todos que atuarão nas equipes de saúde. Além do que, como já mencionado anteriormente, apenas alguns estudantes, só os pertencentes a esse estágio, realizaram essa prática específica.

Por fim, o trabalho com grupos também foi relatado pelos sujeitos do estudo. Essa prática é muito utilizada pelos psicólogos em diversos contextos e com públicos distintos. Caracteriza-se pela ação que se estabelece na junção de pessoas com um objetivo em comum e que busca, por meio de atividades diversas, 
proporcionar a desconstrução e a construção de novos sentidos e significados daquilo que se propõe a trabalhar (Ciampone \& Peduzzi, 2000).

Muitas falas apresentaram enfoque direcionado ao trabalho com grupos, relacionadas principalmente a favorecer um espaço de escuta; inclusive, em algumas situações, utilizando-se como estratégia a roda de conversa:

No estágio básico II, alguns estagiários estão no Hospital Psiquiátrico Santa Cruz trabalhando com os colaboradores do hospital, fazendo roda de conversa ... foi muito legal. . . . Tem outros estagiários que estão fazendo suas práticas em uma outra, inclusive é onde a P2 é psicóloga, eles fazem o estágio na farmácia pública do município. Foi bem interessante também, pois fizeram um trabalho em grupo com as colaboradoras (P6).

A coordenadora do curso também destaca o trabalho com grupo em instituições relacionadas à saúde pública na sua fala: “. . um outro professor está com projetos de estágios no CAPS AD. Lá ele desenvolve trabalho com grupos, eles fazem grupoterapia, além de atividades de apoio" (Coord.).

Importante destacar que alguns estágios tinham como foco a área organizacional e do trabalho, mas, no entanto, estavam sendo realizados em instituições voltadas à saúde pública; assim, esses estudantes acabam por ter contato também com conteúdos relacionados a tal temática ao trabalhar em grupo e ter como público central os colaboradores desse espaço, conforme apresentado em suas falas:

Nosso estágio tinha um foco organizacional, e a equipe com a qual nós realizamos nossa prática foi a equipe de saúde ou, melhor, fizemos um trabalho em grupo com a equipe de saúde .... Mesmo o nosso estágio sendo na área organizacional, tivemos que estudar sobre saúde pública, e escrever uma parte específica sobre isso no nosso material de estágio . . . . Não deixa de ser relacionado com a saúde pública, porque é também uma das atuações ali dentro daquele espaço ... (E2).

Conclui-se que as práticas ofertadas que possuem alguma relação com a temática da saúde pública estão vinculadas aos estágios ofertados ao longo de todo o curso de psicologia, articuladas a diferentes demandas e populações - o Serviço de Atendimento Psicológico do município, o CAPS, o NASF, as UBS, um hospital psiquiátrico, a própria rua, a Associação de Deficientes Físicos, entre outros -, proporcionando acesso a diferentes cenários. É relevante destacar também que o curso apresenta algumas iniciativas que podem ser consideradas inovadoras em se tratando de práticas relacionadas à saúde pública: a sala de espera, o plantão psicológico e o consultório de rua.

As práticas são momentos que oportunizam "encontros" na formação. Assim, possuem grande importância ao permitir ao estudante "ir ao encontro" das demandas da saúde pública. Além de potencializarem seu aprendizado no cenário real, também promovem a diversificação das experiências e vivências que darão suporte para uma prática profissional coerente com o que se espera de um psicólogo quando se insere nas redes de serviços de saúde.

Percebe-se, então, que a formação em psicologia, diante do cenário atual da saúde pública, "deve contemplar o desenvolvimento intelectual dos alunos, preparando-os para atuar frente aos desafios e dilemas com que vão se deparar no cotidiano de suas práticas." (Amendola, 2014, p. 980). Para tanto, há que se diversificar as práticas na perspectiva de uma formação generalista que desenvolva habilidades e competências para os desafios contemporâneos da profissão nessa área.

\section{Considerações finais}

O curso de psicologia analisado acompanha a realidade de outros cursos do Brasil ao apresentar tentativas pontuais de aproximação da formação profissional com a saúde pública, porém ainda carece de avançar no estabelecimento de maior articulação do ensino com o serviço, na diversificação dos cenários de prática e na previsão de atividades interdisciplinares e multiprofissionais durante o processo de formação. Os avanços precisam acontecer principalmente no sentido de abranger, desde a formação, práticas mais integralizadas, possibilitando o encontro com outras áreas de formação e provendo uma perspectiva, de certa forma, mais articulada e multiprofissional.

Faz-se necessário também chamar para o diálogo da formação todos os atores envolvidos no processo. O serviço em saúde pública precisa se fazer cada vez mais presente nas instituições de ensino, e estas, nos serviços de saúde, formando novos discursos e oportunizando novos cenários de prática. 
Estudantes de psicologia e futuros psicólogos precisam assumir o pertencimento ao campo da saúde pública desde a formação. Já estamos inseridos, mas precisamos assumir a saúde pública definitivamente como área de atuação do psicólogo. Isso não fará com que tenhamos perda de qualquer identidade profissional, mas, muito pelo contrário, proporcionará uma ampliação da atuação profissional. Esse pertencimento favorecerá, inclusive, a participação na construção das políticas públicas de saúde de forma mais integrada no que se refere à psicologia na saúde. Mas, para que isso aconteça, o processo de formação profissional precisará prever em sua matriz curricular conteúdos voltados para essa área de saber em diferentes disciplinas, do primeiro ao quinto ano, para todos os estudantes. Também é preciso incluir nos planos de ensino diferentes estratégias pedagógicas para desenvolver habilidades e competências para uma atuação de acordo com a realidade de saúde, ao mesmo tempo em que se necessita ampliar e diversificar os cenários de práticas, prevendo a realização destas em complexidade crescente desde o primeiro ano.

Importante destacar o caráter inacabado das reflexões produzidas na perspectiva da "formação em psicologia" em contraposição às "práticas na saúde pública”. A psicologia avançou, adotou outros discursos, construiu outros campos de saberes, mas ainda há de problematizar a formação dos futuros profissionais para que atuem em concordância com o SUS.

Por fim, é indispensável mencionar as limitações deste estudo, pois, por se tratar de um estudo de caso, apresenta a perspectiva de um curso de psicologia de uma determinada localidade. Recomendam-se novas pesquisas, envolvendo outros cursos de psicologia, bem como com a ampliação do foco para outros aspectos relativos à inserção da saúde pública como tema relevante na formação em psicologia.

\section{Referências}

Abrahão, A. L., \& Merhy, E. E. (2014). Formação em saúde e micropolítica: Sobre conceitos-ferramentas na prática de ensinar. Interface, 18(49), 313-324. https://doi.org/10.1590/1807-57622013.0166

Amendola, M. F. (2014). Formação em Psicologia, demandas sociais contemporâneas e ética: Uma perspectiva. Psicologia: Ciência e Profissão, 34(4), 971-983. https://doi.org/10.1590/1982-370001762013

Azevedo, L. A., Tatmatsu, D. I. B., \& Ribeiro, P. H. R. (2011). Formação em Psicologia e a apropriação do enfoque da atenção primária à saúde em Fortaleza, Ceará. Trabalho, Educação e Saúde, 9(2), 241-264. https://doi.org/ 10.1590/S1981-77462011000200005

Batista, C. B., Carmona, D. S., \& Fonseca, S. L. (2014). Formação em saúde e os cenários de aprendizagem no curso de Psicologia. Psicologia Argumento, 32(78), 17-25. https://doi.org/10.7213/psicol.argum.32.078.DS02

Bernardes, J. S. (2012). A formação em Psicologia após 50 anos do primeiro currículo nacional da Psicologia Alguns desafios atuais. Psicologia: Ciência e Profissão, 32(spe.), 216-231. https://doi.org/10.1590/ S1414-98932012000500016

Ceccim, R. B., \& Feuerwerker, L. (2004). Mudança na graduação das profissões da saúde sob o eixo da integralidade. Cadernos de Saúde Pública, 20(5), 1400-1410. https://doi.org/10.1590/S0102-311X2004000500036

Ciampone, M. H. T., \& Peduzzi, M. (2000). Trabalho em equipe e trabalho em grupo no Programa de Saúde da Família. Revista Brasileira de Enfermagem, 53(spe.), 143-147. https://doi.org/10.1590/S0034-71672000000700024

Conselho Nacional de Educação. (2011). Resolução no 5, de 15 de março de 2011. Institui as Diretrizes Curriculares Nacionais para os cursos de graduação em Psicologia, estabelecendo normas para o projeto pedagógico complementar para a Formação de Professores de Psicologia. Ministério da Educação, Câmara de Educação Superior.

Conselho Federal de Psicologia. (2013). Referências Técnicas para a Atuação de Psicólogas(os) em Políticas Públicas de Álcool e Outras Drogas. Conselho Federal de Psicologia.

Dimenstein, M. (1999). (Des)caminhos da formação profissional do psicólogo no Brasil para a sua atuação no campo da saúde pública. Revista do Departamento de Psicologia da UFF, 11(1), 17-25.

Doescher, A. M. L., \& Henriques, W. M. (2012). Plantão Psicológico: Um encontro com o outro na urgência. Psicologia em Estudo, 17(4), 717-723.

Drulla, A. G., Alexandre A. M. C., Rubel F. I., \& Mazza, V. A. (2009). A visita domiciliar como ferramenta ao cuidado familiar. Cogitare Enfermagem, 14(4), 667-674. http://doi.org/10.5380/ce.v14i4.16380 
Ferreira, C. P. S., Rozendo, C. A., \& Melo, G. B. (2016). Consultório na Rua em uma capital do Nordeste brasileiro: O olhar de pessoas em situação de vulnerabilidade social. Cadernos de Saúde Pública, 32(8), 1-10. https://doi.org/ 10.1590/0102-311X00070515

Freitas, P. H., Colomé, J. S., Carpes, A. D., Backes, D. S., \& Beck, C. L. C. (2013). Repercussões do pet-Saúde na formação de estudantes da área da saúde. Escola Anna Nery: Revista de Enfermagem, 17(3), 496-504. https://doi.org/ $10.1590 /$ S1414-81452013000300013

Guareschi, N. M. F., Dhein, G., Reis, C., Machry, D. S., \& Bennemann, T. (2009). Formação em Psicologia e o profissional da saúde para o SUS (Sistema Único de Saúde). Arquivos Brasileiros de Psicologia, 61(1), 35-45.

Leal, J. A. L., Melo, C. M. M., Veloso, R. B. P., \& Juliano, I. A. (2015). Novos espaços de reorientação para formação em saúde: Vivências de estudantes. Interface, 19(53), 361-371. https://doi.org/10.1590/1807-57622014.0107

Londero, M. F. P., Ceccim, R. B., \& Bilibio, L. F. S. (2014). Consultório de/ na rua: Desafio para um cuidado em verso na saúde. Interface, 18(49), 1-10. https://doi.org/10.1590/1807-57622013.0738

Macedo, J. P., \& Dimenstein, M. (2011). Formação do psicólogo para a saúde mental: A psicologia piauiense em análise. Interface, 15(39), 1145-1157. https://doi.org/10.1590/S1414-32832011005000021

Matos, E., Pires, D. E. P., \& Campos, G. W. S. (2009). Relações de trabalho em equipes interdisciplinares: Contribuições para a constituição de novas formas de organização do trabalho em saúde. Revista Brasileira de Enfermagem, 62(6), 863-869. https://doi.org/10.1590/S0034-71672010000500013

Minayo, M. C. S. (2012). Análise qualitativa: Teoria, passos e fidedignidade. Ciência \& Saúde Coletiva, 17(3), 621-626. https://doi.org/10.1590/S1413-81232012000300007

Minayo, M. C. S. (2014). O desafio do conhecimento: Pesquisa qualitativa em saúde. Hucitec.

Moreira, S. V. (2005). Análise documental como método e como técnica. In J. Duarte, \& A. Barros (Org.), Métodos e técnicas de pesquisa em comunicação (pp. 269-279). Atlas.

Oliveira, I. F., Dantas, C. M. B., Costa, A. L. F., Silva, F. L., Alverga, A. R., Carvalho, D. B., \& Yamamoto, O. H. (2004). O psicólogo nas unidades básicas de saúde: Formação acadêmica e prática profissional. Interações, 9(17), 71-89.

Pan, M., Zonta, G. A., \& Tovar, A. (2015). Plantão Institucional: Relato de experiência de uma intervenção psicológica na UFPR. Psicologia em Estudo, 20(4), 555-562. https://doi.org/10.4025/psicolestud.v20i4.27594

Paparelli, R. B., \& Nogueira-Martins, M. C. F. (2007). Psicólogos em Formação: Vivências e demandas em Plantão Psicológico. Psicologia: Ciência e Profissão, 27(1), 64-79. https://doi.org/10.1590/S1414-98932007000100006

Pietroluongo, A. P. C., \& Resende, T. I. M. (2007).Visita Domiciliar em Saúde Mental: O papel do psicólogo em questão. Psicologia: Ciência e Profissão, 27(1), 22-21. https://doi.org/10.1590/S1414-98932007000100003

Poppe, A. R. S., \& Batista, S. H. S. S. (2012). Formação em Psicologia no contexto das Diretrizes Curriculares Nacionais: Uma discussão sobre os cenários de prática em saúde. Psicologia: Ciência e Profissão, 32(4), 986-999. https://doi.org/10.1590/S1414-98932012000400016

Ramos-Cerqueira, A. T. A., Torres, A. R., Martins, S.T.F., \&Lima, M.C.P. (2009). Um estranhoà minhaporta: Preparando estudantes de Medicina para visitas domiciliares. Revista Brasileira de Educação Médica, 33(2), 276-281. https://doi.org/10.1590/S0100-55022009000200016

Rebouças, M. S. S., \& Dutra, E. (2010). Plantão Psicológico: Uma Prática Clínica da Contemporaneidade. Revista da Abordagem Gestáltica, 16(1), 19-28.

Reis, C., \& Guareschi, N. M. F. (2010). Encontros e desencontros entre psicologia e política: Formando, deformando e transformando profissionais de saúde. Psicologia Ciência e Profissão, 30(4), 854-867. https://doi.org/10.1590/ S1414-98932010000400014

Rosa, J., Barth, P. O., \& Germani, A. R. M. (2011). A sala de espera no agir em saúde: Espaço de educação e promoção à saúde. Perspectiva, 35(129), 121-130.

Rotolo, L. M., \& Zurba, M. C. (2011). Educação em saúde na atenção básica: Estratégias do fazer do psicólogo para a promoção da saúde. In M. C. Zurba (Org.). Psicologia e saúde coletiva (pp. 123-138). Tribo da Ilha.

Santos, D. S., Andrade, A. L. A., Lima, B. S. S., \& Silva, Y. N. (2012). Sala de espera para gestantes: Uma estratégia de educação em saúde. Revista Brasileira de Educação Médica, 36(1 Suppl. 2), 62-67. https://doi.org/10.1590/ S0100-55022012000300010 
Psicologia: Ciência e Profissão 2021 v. 41nspe2, e194293, 1-13.

Schmidt, M. L. S. (2004). Plantão psicológico, universidade pública e política de saúde mental. Estudos de Psicologia, 21(3), 173-192. https://doi.org/10.1590/S0103-166X2004000300003

Seixas, P. S., \& Yamamoto, O. H. (2012). A inserção e a atuação profissional do psicólogo no campo das políticas sociais no Rio Grande do Norte. Psicologia Argumento, 30(70), 477-489. http://doi.org/10.7213/psicol.argum.6135

Seixas, P. S., Coelho-Lima, F, Silva, S. G., \& Yamamoto, O. H. (2013). Projeto Pedagógico de Curso e formação do psicólogo: Uma proposta de análise. Revista Semestral da Associação Brasileira de Psicologia Escolar e Educacional, 17(1), 113-122. https://doi.org/10.1590/S1413-85572013000100012

Silva, C. A., \& Yamamoto, O. H. (2013). As políticas sociais na formação graduada do psicólogo no Piauí. Psicologia: Ciência e Profissão, 30(4), 824-839. https://doi.org/10.1590/S1414-98932013000400005

Silva, F. P., Frazão, I. S., \& Linhares, F. M. P. (2014). Práticas de saúde das equipes dos Consultórios de Rua. Cadernos de Saúde Pública, 30(4), 805-814. https://doi.org/10.1590/0102-311X00100513

Sousa, V. D., \& Cury, V. E. (2009). Psicologia e atenção básica: Vivências de estagiários na Estratégia de Saúde da Família. Ciência \& Saúde Coletiva, 14(Suppl. 1), 1429-1438. https://doi.org/10.1590/S1413-81232009000800016

Spink, M. J. P. (2013). Psicologia social e saúde: Práticas, saberes e sentidos. Vozes.

Teixeira, E. R., \&Veloso, R. C. (2006). O grupo em sala de espera: Território de práticas e representações em saúde. Texto \& Contexto Enfermagem, 15(2), 320-325. https://doi.org/10.1590/S0104-07072006000200017

Tondin, M. C., Barros Neta, M. A. P., \& Passos, L. A. (2013). Consultório de Rua: Intervenção ao uso de drogas com pessoas em situação de rua. Revista de Educação Pública, 22(49/2), 485-501. https://doi.org/ 10.29286/ rep.v22i49/2.929

Veiga, I. P. A. (1992). A prática pedagógica do professor de Didática. Papirus.

Vieira, C., \& Oliveira, W. (2011). O papel do psicólogo na atenção primária na era NASF: Ações, concepções e perspectivas. In M. C. Zurba (Org.), Psicologia e saúde coletiva (pp. 103-121). Tribo da Ilha.

Yin, R. K. (2007). Estudo de caso: planejamento e métodos. Bookman.

\section{Taíse Signorini}

Docente e coordenadora do curso de Psicologia da Universidade Paranaense (Unipar), Francisco Beltrão - PR. Brasil. E-mail: taise@prof.unipar.br

(1) https://orcid.org/0000-0001-7863-0940

\section{Fátima Ferretti}

Docente do programa stricto sensu em Ciências da Saúde da Universidade Comunitária da Região de Chapecó (Unochapecó), Chapecó - SC. Brasil.

E-mail: ferrettifisio@yahoo.com.br

(1) https://orcid.org/0000-0002-0326-2984

\section{Maria Elisabeth Kleba da Silva}

Docente do programa stricto sensu em Ciências da Saúde da Unochapecó, Chapecó - SC. Brasil.

E-mail: 1kleba@unochapeco.edu.br

(1) https://orcid.org/0000-0002-6703-8375

Endereço para envio de correspondência:

Rua Diego Emanuel Prigo, 43, São Cristovão. CEP: 85601-379. Francisco Beltrão - PR. Brasil. 
Recebido 12/04/2018

Aceito 30/05/2019

Received 04/12/2018

Approved 05/30/2019

Recibido 12/04/2018

Aceptado 30/05/2019

Como citar: Signorini, T., Ferretti, F, \& Kleba, M. E. S. (2021). Práticas em psicologia na saúde pública: Aproximando cenários e contextos. Psicologia: Ciência e Profissão, 41, 1-13. https://doi.org/10.1590/1982-3703003194293

How to cite: Signorini, T., Ferretti, F., \& Kleba, M. E. S. (2021). Practices in psychology in public health: Approaching scenarios and contexts. Psicologia: Ciência e Profissão, 41, 1-13. https://doi.org/10.1590/1982-3703003194293

Cómo citar: Signorini, T., Ferretti, F., \& Kleba, M. E. S. (2021). Prácticas en psicología en la salud pública: Aproximando escenarios y contextos. Psicologia: Ciência e Profissão, 41, 1-13. https://doi.org/10.1590/1982-3703003194293 